\title{
Trust your gut or think carefully? Examining whether an intuitive, versus a systematic, mode of thought produces greater empathic accuracy.
}

\section{Citation}

Ma-Kellams, Christine, and Jennifer Lerner. 2016. “Trust Your Gut or Think Carefully? Examining Whether an Intuitive, Versus a Systematic, Mode of Thought Produces Greater Empathic Accuracy." Journal of Personality and Social Psychology 111 (5): 674-685. doi:10.1037/ pspi0000063.

\section{Permanent link}

http://nrs.harvard.edu/urn-3:HUL.InstRepos:37093806

\section{Terms of Use}

This article was downloaded from Harvard University's DASH repository, and is made available under the terms and conditions applicable to Open Access Policy Articles, as set forth at http:// nrs.harvard.edu/urn-3:HUL.InstRepos:dash.current.terms-of-use\#OAP

\section{Share Your Story}

The Harvard community has made this article openly available.

Please share how this access benefits you. Submit a story.

\section{Accessibility}




\section{Trust Your Gut or Think Carefully? Examining Whether an I ntuitive, Versus a Systematic, Mode of Thought Produces Greater Empathic Accuracy Faculty Research Working Paper Series}

\section{Christine Ma-Kellams}

University of La Verne

Jennifer S. Lerner

Harvard Kennedy School

\section{April 2016}

\section{RWP16-017}

The views expressed in the HKS Faculty Research Working Paper Series are those of the author(s) and do not necessarily reflect those of the John F. Kennedy School of Government or of Harvard University. Faculty Research Working Papers have not undergone formal review and approval. Such papers are included in this series to elicit feedback and to encourage debate on important public policy challenges. Copyright belongs to the author(s). Papers may be downloaded for personal use only. 
RUNNING HEAD: Mode of Thought and Empathic Accuracy

Trust Your Gut or Think Carefully?

Examining Whether an Intuitive, Versus a Systematic, Mode of Thought Produces Greater Empathic Accuracy

Christine Ma-Kellams, Univeristy of La Verne

Jennifer S. Lerner, Harvard University

Draft, 2016.3.26

Manuscript Under Review

Contact: Christine Ma-Kellams, cma-kellams@laverne.edu

Keywords: empathic accuracy, mode of thought, feeling, emotion, intuition, person perception, individual differences 


\begin{abstract}
Cultivating successful personal and professional relationships requires the ability to accurately infer the feelings of others - i.e., to be empathically accurate. Some are better than others at this, which may be explained by mode of thought, among other factors. Specifically, it may be that empathically-accurate people tend to rely more on intuitive rather than systematic thought when perceiving others. Alternatively, it may be the reverse - that systematic thought increases accuracy. In order to determine which view receives empirical support, we conducted four studies examining relations between mode of thought (intuitive versus systematic) and empathic accuracy. Study 1 revealed a lay belief that empathic accuracy arises from intuitive modes of thought. Studies 2-4, each using executive-level professionals as participants, demonstrated that (contrary to lay beliefs) people who tend to rely on intuitive thinking also tend to exhibit lower empathic accuracy. This pattern held when participants inferred others' emotional states based on (a) in-person face-to-face interactions with partners (Study 2) as well as on (b) pictures with limited facial cues (Study 3). Study 4 confirmed that the relationship is causal: experimentally inducing systematic (as opposed to intuitive) thought led to improved empathic accuracy. In sum, evidence regarding personal and social processes in these four samples of working professionals converges on the conclusion that -- contrary to lay beliefs -- empathic accuracy arises more from systematic thought than from gut intuition.
\end{abstract}


As Charles Darwin (1872/1999) described, the ability to recognize "The Expression of Emotion in Man and Animals" plays a profound role in all societies, even non-human primate societies. Examples abound. Close relationship partners must discern whether a comment or facial expression is meant to be critical or innocent, negotiators need to gauge the likelihood of achieving an agreement, law enforcement officers must accurately infer the intent behind a stranger's actions, and peacekeepers around the globe must put themselves "in the shoes" of those they are trying to help in order to be successful.

\section{Empathic accuracy}

Long after Darwin's time, empirical studies have confirmed that the human ability to discern the internal affective experiences of others, also known as empathic accuracy ${ }^{1}$ (Ickes et al., 1990; Levenson \& Ruef, 1992), assists in a host of adaptive processes, such as conflict resolution (Papp, Kouros \& Cummings, 2010), relationship outcomes (Gleason, JensenCampbell \& Ickes, 2009; Haugen, Welsh, \& McNutty, 2008; Kilpatrick, Bissonette, \& Rusbult, 2002; Lorimer \& Jowitt, 2009; Verhofstadt, Buysse, Ickes, Davis, \& Devoldre, 2008), accommodative behavior (Kiplatrick, Bissonnette, \& Rusbult, 2002), psychological adjustment (Simpson et al., 2011), communication effectiveness (e.g., Mehrabian \& Reed, 1968), and negotiation (Fisher \& Shapiro, 2005).

A growing body of research elucidates the contexts and targets that can increase empathic accuracy. Among others, these include: target familiarity (Maragoni, Garcia, Ickes, \& Teng, 1995; Thomas et al., 1997); and contexts with: (a) monetary incentives (i.e., payment for higher empathic accuracy, which has been shown both to increase accuracy—Klein \& Hodges, 2007, and decrease it, depending on the context or the amount of money offered-Ma-Kellams \& Blascovich, 2012a); (b) motivation more generally (for review, see Hall, Blanch, Horgan, 
Murphy, Rosip \& Mast, 2009); (c) attraction (Ickes, Stinson, Bisonnette, \& Stella, 1990); and (d) the interaction of culture and relationship status (namely, people from Eastern vs. Western cultural backgrounds may be more or less accurate as a function of the relationship with the target at hand-Ma-Kellams \& Blascovich, 2012b; but see also Soto \& Levenson, 2009). Taken together, such effects can be explained by a motivational theory of empathy. For example, Zaki (2014) proposed that some empathic processes are automatic (e.g., vicarious experiences, experience sharing, mimicry, emotional contagion) while others are only activated in contexts that motivate deeper effort.

A smaller body of research has begun to elucidate the characteristics of perceivers, identifying ways in which accurate perceivers differ from their less accurate counterparts. The most frequently identified characteristics of accurate perceivers are female gender (Klein \& Hodges, 2001; Stinson \& Ickes, 1992) and the absence of an Autism Spectrum Disorder (Hodges, Lewis \& Ickes, 2015).

Perceiver's mode of thought and empathic accuracy. As a complement to the predictors described above, it is useful to ask whether mode of thought — either as reflected in individual differences or in situationally-primed processes - predicts empathic accuracy. Specifically, it may be that empathically-accurate people tend to rely more on intuitive (see, for example, Gigerenzer, 2007; Klein, 2003; Myers, 2002) versus systematic thought when perceiving others. Alternatively, it may be the reverse - that systematic thought (see, for example, Frederick, 2005) increases accuracy. To date, however, little is known about how intuitive versus systematic mode of thought relates to the special kind of accuracy involved in perceiving another's feelings. ${ }^{2}$ It may be that in the unique domain of emotion, survival needs have resulted in the fact that humans are evolutionarily wired to read others' feelings quickly, automatically, and accurately 
(Öhman, 2000; Keltner, Oatley \& Jenkins, 2014) (“Is this person about to hit me or embrace me?"). Tracy and Robins (2008) found, for example, that not only can most people quickly recognize basic emotions associated with static facial expressions, but also that thinking more carefully does not significantly improve accuracy except in a few cases. Consistent with this speculation, we review literature on ways in which intuitive mode of thought (as opposed to systematic) may relate to empathic accuracy in complex social interactions, broadly defined.

\section{Does intuitive thinking improve empathic accuracy?}

Although we find no research directly addressing the link between intuition and empathic accuracy, adjacent lines of theory can be informative. First, a number of early theories of empathy have highlighted empathy's intuitive and automatic nature. Adam Smith, in his Theory of Moral Sentiments (1790/2002), highlighted the natural, reflexive nature of our ability to know and feel the experiences of another person. Other philosophers, such as Vischer (1873) and Lipps (1903), along with psychologists like Tichener (1909) and McDougall (1908/2003), similarly endorsed this view of empathic processes as automatic and unconscious. In more recent decades, a growing number of studies from across psychological sub-disciplines have found that individuals tend to automatically and involuntarily share in others' experiences (for a review, see Zaki, 2014). For example, infants instinctively mimic their mothers' emotional expressions (Haviland \& Lelwica, 1987), and adults tend to mimic others' facial movements as well (Chartrand \& van Baaren, 2009; Hess \& Blairy, 2001; Lundqvist, 1995; Niedenthal, Brauer, Halberstadt, \& Innes-Ker, 2001).

At a broad level, theorists have proposed that the very existence of intuitive thinking is a form of "ancient biological wisdom" (Myers, 2002, p. 33) that has evolved to allow people to use prior experience and learning, including pattern recognition-i.e., matching relevant external 
cues to commonly occurring configurations (Agor, 1989; Harper, 1989; Klein, 1998; for a more recent review, see Hodgkinson, Langan-Fox, \& Sadler-Smith, 2008). Consistent with these ideas, neuroimaging research has found that intuitive thinking is the byproduct of implicit learning processes, leading such social neuroscientists as Lieberman (2000) to conclude that there are conditions under which intuition can lead to better outcomes than deliberative thinking.

Matching mode of thought to type of judgment. Along similar lines, Kruglanski and Gigerenzer's (2011) contend that intuition can be as accurate as deliberate thinking in certain kinds of judgments. Their theory holds that, since both intuitive and deliberative approaches are premised on common cognitive strategies, which type of thinking is more accurate in a given situation depends on whether the underlying strategy matches the demands of the context. Kruglanski and Gigerenzer (2011) argue that both intuitive and deliberative thinking are rulebased (and can rely on the same rules); thus, one type of thinking is not more or less accurate than the other, but rather, accuracy depends on the match between the rule and the context or context. Related papers by Gigerenzer and colleagues have also explicitly argued that intuition is a highly adaptive decision-making tool (for reviews, see Gigerenzer 2008; Gigerenzer \& Gaissmaier, 2011; Goldstein \& Gigerenzer, 2002).

Furthermore, a broader body of empirical research has provided compelling evidence that "thinking too much" can reduce the quality of judgments and decisions. A prime example is the finding that verbalizing what is "non-verbalizable" can hinder the psychological process at hand (Fallshore \& Schooler, 1995; Nisbett \& Wilson, 1977; Schooler \& Engstler-Schooler, 1990; Schooler, Ohlsson, \& Brooks, 1993; Wilson \& Schooler, 1991). For example, individuals who were asked to focus and report on the details of faces exhibited worse recognition of such faces (Diamond \& Carey, 1986; Fallshore \& Schooler, 1995; Schooler, Ryan \& Reder, 2014). Overall, 
research suggests that 1) verbalization is a form of controlled, detailed, systematic processing, and 2) such processing leads to the de-emphasis of visual and configural cues about the relationship among different features. Given that emotions are generally complex phenomena that cannot be captured by focusing on isolated cues and that rely heavily on non-verbal cues in particular, the argument can be made that controlled, detailed processing would interfere with the ability to successfully process emotional information.

Moroever, related phenomenon like the "deliberation-without-attention" finding is similarly premised on the idea that systematic, deliberative thought is not always advantageous (Dijksterhuis, Bos, Nordgren \& van Baaren, 2006). According to this paradigm, thinking effortfully about complex choices leads to worse, rather than better, outcomes (Dijksterhuis et al., 2006).

Thus, although it may be tempting for scholars (and others who like to think systematically) to assume that systematic thought processes are inherently superior - i.e., more likely to produce empathically accurate judgments — the empirical record of relations between systematicity of thought and judgment accuracy reveals a far more nuanced reality. ${ }^{3}$

\section{Does systematic thinking improve empathic accuracy?}

In contrast to the foregoing theories and evidence, it can also be argued that systematic thinking may promote greater empathic accuracy than intuitive thinking. For example, at the heart of such well-supported person-perception theories as Fiske and Neuberg's continuum model of impression formation (1990) is the assumption that complex, individuated processingwhich requires effortful, careful thinking-generates more accurate impressions than spontaneous, category-based inferences. While Fiske and Neuberg contend that quick, categorical impressions may be useful under certain conditions, they find that these impressions 
are likely to trigger less-than-optimal impressions of others. In addition, evidence for the superiority of systematic thought for accuracy derives from research on perspective-taking (e.g., the notion that mental state reasoning starts with intuitive responses but should involve effortful correction processes - for review, see Epley \& Waytz, 2010).

These findings are consistent with the idea that empathic accuracy may be difficult to achieve precisely because it requires systematic thought from otherwise busy perceivers experiencing cognitive capacity constraints. Consistent with this view, individuals often fail to understand the experiences of perceived out-group members (e.g., Avenanti, Sirigu, \& Aglioti, 2010; Cikara \& Van Bavel, 2014; Gutsell \& Inzlicht, 2010; Harris \& Fiske, 2006, 2007; Hein, Silani, Preuschoff, Batson, \& Singer, 2010; Leyens et al.,2000; Ma-Kellams \& Blascovich, 2012a; Mitchell, Ames, Jenkins, \& Banaji, 2009; Xu, Zuo, Wang, \& Han, 2009), and experts often neglect to show empathy toward those they work with (e.g., health professionals toward patients, Cheng et al., 2007; Decety, Yang, \& Cheng, 2010; Marquié et al., 2003; Sloman, Rosen, Rom, \& Shir, 2005).

\section{The present project}

In sum, conflicting implications arise from the foregoing evidence. Attempting to reconcile these, we test the link between empathic accuracy and mode of thought across four studies. In Study 1, we examine individuals' lay theories about the nature of empathic accuracy and the extent to which lay people assume that mind-reading is an intuitive or a systematic process requiring cognitive reflection. In Study 2, we test the relationship between individual differences in mode of thought and empathic accuracy using a measure involving an in-person dyadic interaction between professional peers (Kraus, Côté \& Keltner, 2010; Ma-Kellams \& Blascovich, 2012a, 2012b). In Study 3, we test the same phenomena using a different measure of 
empathic accuracy: the Reading the Mind in the Eyes Test (RMET), which requires individuals to discern the emotions expressed in static photographs of the eye region of a series of faces (Baron-Cohen et al., 2001). ${ }^{4}$ In Study 4, we test the causal relationship between intuitive thinking and empathic accuracy by experimentally inducing a mindset favoring intuition versus systematic thinking.

\section{Study 1}

We first sought to assess whether lay people believe that mode of thought influences empathic accuracy. The idea that intuition is a superior mode of thought for achieving empathic accuracy may have inherent appeal. Indeed, praise for intuitive processing can be found in a wide range of popular books, some from serious scholars (see Klein, 2003; Myers, 2002; Gigerenzer, 2008) and some from professional practice experts. It is also advocated in several national security contexts, as evidenced by the U.S. Navy’s $\$ 3.85$ million dollar program of research on intuitive thinking processes (Channing, 2012).

To address this question, we conducted a study measuring people's beliefs about the role of intuition versus systematic thinking in promoting empathic accuracy.

\section{Participants}

314 participants $($ Mage $=34.40, S D=11.13 ; 46 \%$ male $)$ were recruited via Amazon Mechanical Turk (Mturk), an online crowdsourcing platform. Sample size was pre-determined based on the predicted effect sizes and the between-subjects format of the design.

\section{Method}

In a one-factor, 3-level design, participants were asked to decide how to optimally coach employees for a particular job. Each participant received one of three possible descriptions. In one the goal of the job emphasized empathic accuracy, in another it de-emphasized empathic ac- 
curacy, and in a third (control) condition no-goal was given. At first readers concerned about parsimony might think that the hypothesis could be tested with a smaller design. However, if we ran only the EA job condition and found within that condition (via a chi-square test) that people preferred intuitive over systematic approaches, such a result would not allow us to rule out an alternative explanation -- that people generally preferred intuition across contexts, regardless of whether empathic accuracy was involved.

The rationale for adding a decreased-empathic-accuracy condition is that it allowed us to test not only whether respondents perceived an association between intuition and empathic accuracy but also whether respondents perceived an association between systematic thought (the opposite of intuition) and lack of empathic accuracy.

In the empathic accuracy (EA) job condition, participants were instructed that the goal was to help employees to accurately infer the feelings of others (the text read: "Please imagine that the company where you work has hired a new employee. Your job is to help that employee to become better at inferring the feelings of other people)." Participants were then asked to choose between two options for coaching. Options read: "tell employees to think in an intuitive and instinctive way" or "tell employees to think in an analytical and systematic way." In the nonEA job condition, participants were told that the goal was to help employees become less able to infer others' feelings, whereas those in the control condition were simply asked to choose the guideline they would prefer to give when they are helping an employee.

\section{Results}

Separate chi-square tests were conducted for each condition to test whether the preference for intuitive versus systematic approaches deviated from chance (i.e., 50/50). Results revealed a strong, systematic deviation. In the EA job condition $(n=100)$, seventy- 
four participants chose the intuitive approach and twenty six chose the systematic approach; this deviation from the expected values of 50/50 was significant, $\chi 2=23.04, \mathrm{df}=$ $1, p<.001$. Thus, a significant association emerged between choosing the intuitive approach and a job demanding empathic accuracy. Results also revealed a significant association between choosing systematicthought and a job that demanded the absence of empathy. In the non EA-condition $(n=106)$, twenty-two participants chose the intuitive approach and eighty-four chose the systematic approach; this deviation from the expected values of 53/53 was also significant, $\chi 2=36.26, \mathrm{df}=1, p<.001$. Importantly, in the control condition $(\mathrm{n}=$ 108), the breakdown for intuitive versus systematic mode of thought was forty six and sixty two, respectively; this deviation from the expected values of 54/54 was not significant, $\chi^{2}=$ $2.37, \mathrm{df}=1, p=.12$. In other words, without a specific goal regarding empathy, respondents were equally likely choose the intuitive versus the systematic approach. Taking all results together, the data reveal that assigning a goal of empathic accuracy activates preferences for intuitive modes of thought whereas assigning a goal of deemphasizing empathic accuracy activates preferences for analytic modes of thought.

To check for robustness, we also compared each of the experimental conditions (i.e., EA job and non-EA job) with the control condition in separate binary logistic regressions. A binary logistic regression comparing responses in the EA job condition vs. control condition revealed that condition had a significant effect on the forced choice outcome of choosing intuitive vs. systematic thinking. The Wald criterion demonstrated that condition made a significant contribution to prediction, $B=.67, S E=.15, p<.001$. An $\operatorname{Exp}(\mathrm{B})$ odds ratio of 1.96 indicates that moving from the EA job to the control condition was associated with a significantly increased likelihood of choosing systematic thinking (or conversely, moving from 
the control condition to the EA job was associated with an increased likelihood of choosing intuitive thinking). ${ }^{5}$

A separate binary logistic regression comparing responses in the non-EA job condition vs. control condition found that the effect of condition was also significant on the forced choice outcome of choosing intuitive vs. systematic thinking. The Wald criterion demonstrated that condition made significant contributions to prediction, $B=-1.04, S E=.31, p=.001 . \mathrm{An} \operatorname{Exp}(\mathrm{B})$ of 0.35 indicates that moving from the non-EA job to the control condition was associated with a decreased likelihood of choosing systematic thinking (or conversely, moving from the control condition to the non-EA job was associated with an increased likelihood of choosing systematic thinking).

\section{Discussion}

This study provides causal evidence that lay individuals associate empathic accuracy with an intuitive modes of thought. It also provides evidence that lay individuals associate the absence of empathic accuracy with systematic, analytic modes of thought. To test whether this lay belief about the association between mode of thought and empathic accuracy receives empirical support in actual behavior, we conducted three more studies.

\section{Study 2}

\section{Participants}

A large community sample that consisted of participants from several executiveeducation programs at Harvard University (designed for senior-level professionals) participated as part of a larger study at the Harvard Decision Science Laboratory (HDSL) in Cambridge, Massachusetts. Program participants were invited to complete a series of questionnaires in the HDSL. In exchange for their voluntary participation, participants received individualized 
feedback about their responses after the study was over. The sample consisted of international and U.S.-born participants $(N=72,47=$ male; Mage $=47.11$, SDage $=7.81 ; 72 \%$ EuropeanAmerican, 14\% African or African-American, 6\% Asian, 4\% Latin-American, and 4\% other). Sample size was determined based on enrollment in Harvard's Executive Education program. By studying actual professionals and managers, we were able to test empathic accuracy in an ecologically, externally valid way among a group of people for whom empathic accuracy is crucial (e.g., in negotiation outcomes-Elfenbein, Foo, White, Tan \& Aik, 2007; Galinsky, Maddux, Gilin \& White, 2008; Neale \& Bazerman, 1983, workplace satisfaction-Byron, 2007, and workplace performance_-Elfenbein \& Ambady, 2002; Rosenthal, Hall, DiMatteo, Rogers \& Archer, 1979).

\section{Method}

Following the procedures used by Kraus et al. (2010), participants completed a mock interview as a new measure of empathic accuracy. Upon arrival at the lab, they were randomly paired and assigned to the role of either the interviewer or interviewee. Interviewers were instructed to ask their interviewee a scripted set of three typical interview questions (e.g., "What is your greatest strength and weakness?"). Pairs were given three minutes to complete the mock interview. Next, participants completed two separate Positive and Negative Affect Schedules (PANAS; Watson, Clark \& Tellegen, 1988), one assessing their own emotions during the interview and one assessing what they perceived their partner's emotions to be during the interview; participants rated how they felt, as well as how they thought their partners felt, on 20 different mood items (e.g., interested, distressed, proud, nervous) on a scale ranging from 1 (not at all) to 5 (extremely). 
In addition, participants completed a three-item Cognitive Reflection Test (CRT;

Frederick, 2005). All three items are math problems with intuitively appealing but incorrect answers. For example, the immediate, intuitive response to the question "A bat and a ball cost $\$ 1.10$ in total. The bat costs $\$ 1.00$ more than the ball. How much does the ball cost?" is $\$ 0.10$; the correct answer is actually $\$ 0.05$. Choosing the immediate and reflexive, but incorrect, answer signals greater reliance on intuition and less reliance on systematic thinking. Performance on the CRT has been reliably associated with measures of self-reported cognitive style (e.g., Need for Cognition-Cacioppo \& Petty, 1982) and judgment and decision making (i.e., susceptibility to classic heuristics and biases-Frederick, 2005; Toplak, West, \& Stanovich, 2011).

Participants subsequently completed demographic questions about their age, gender, education, and position at work.

\section{Results and Discussion}

Prior to the main analyses, empathic accuracy was calculated by computing intracorrelations between participants' inferences about their partner's emotions and their partner's own assessments of their emotions (see Anderson, Keltner \& John, 2003; Gonzalez \& Griffin, 1997).

A test of the main hypothesis revealed that CRT scores predicted empathic accuracy such that higher systematicity was associated with higher accuracy, $\beta=.24, t(71)=2.07, p=.042$. Adding demographic covariates (i.e., age and gender) did not change the pattern of results: $\beta=$ $.25, t(69)=2.04, p=.045$; for complete regression tables, see Table 2 .

In order to further assess the robustness of the relationship, we also explored the role of social power, an additional covariate that past studies have shown to be a reliable predictor of empathic accuracy (e.g., Bombari, Schmid Mast, Brosch, \& Sander, 2013; Côté et al., 2011). We 
examined two different operationalizations of power: structural power (i.e., whether participants were currently in a leadership or managerial role at work) and situational power (i.e., the role they played during the interview-the interviewer vs. the interviewee). Structural power was assessed with the question "Are you responsible for managing others?" (yes/no); situational power was assessed by asking participants to check whether they played the interviewer or interviewee. Both operationalizations were self-reported and coded dichotomously. The majority of participants had structural power (89\%); participants were evenly divided between those who did have situational power and those who didn't (i.e., half were interviewers and the other half were interviewees); for full correlation matrix of the link between power and our other variables of interest, see Table 1. Somewhat surprisingly, including power as a covariate also did not change the relationship between CRT responses and empathic accuracy; see Table 2 for full regression tables. It may be that in this sample of executives the minor role assignment did not affect their underlying sense of power.

For the sake of comparability with other studies of empathic accuracy, we also recomputed accuracy scores by taking the absolute difference between the participant's rating of their partner's emotions on each of the PANAS items and the partner's own rating on the item, following procedures used by Côté et al. (2011), Kraus et al. (2010), and Ma-Kellams and Blascovich (2012a, 2012b). Scores across targets were averaged to yield an overall measure of empathic accuracy for each participant, with lower scores reflecting greater accuracy. Doing so yielded the same pattern of results; participants who scored higher on the CRT (i.e., those who engaged in more systematic thinking) exhibited greater empathic accuracy during the mock interview (i.e., lower absolute differences between their assessment of their partners' experiences and their partners' self-assessments), $\beta=-.33, t(71)=2.96, p=.004$. This relationship remained 
significant when we controlled for gender, $\beta=-.34, t(70)=2.92, p=.005$, as well as when other demographic controls were added as well (i.e., age and education; see Table 2), $B=-.33, t(69)=$ $2.74, p=.008$. Moreover, the effect of greater systematic thinking on empathic accuracy is robust both when structural power is controlled for, $\beta=-.32, \mathrm{t}(70)=2.77, \mathrm{p}=.007$, and when situational power is controlled for, $\beta=-.34, t(70)=2.95 p=.004$. For full regression tables with absolute difference scores as the outcome of interest, see Table 3 .

Individuals who engaged in more systematic thinking, as reflected by their CRT performance, were more accurate at reading their partner's experience during a live mock interview, even when controlling for demographic variables previously shown to be linked to the CRT (Frederick, 2005), such as gender and education. Likewise, this relationship did not change when a factor previously shown to be related to empathic accuracy (i.e., power, Bombari, 2013; Côté et al., 2011) was taken into account.

Having established a connection between systematic thought and empathic accuracy, we next wondered if the relationship is context dependent. One possibility is that systematic thinking may improve empathic accuracy only during complex, dynamic interactions-e.g., the live, dyadic interviews conducted in Study 2. Would systematic thinking also aid empathic accuracy in reading static emotional cues? To answer this question, we conducted Study 3, using a different task -- one that involved reading static facial expressions rather than interacting with another in conversation. We also sought to increase the stringency of Study 3 by adding an additional control variable - level of intelligence. We chose intelligence because several studies have found that the CRT is correlated with intelligence and therefore it is possible that intelligence itself drives the relationship between CRT and improved empathic accuracy rather than mode of thought per se. 


\section{Study 3}

\section{Participants}

A different group of international and U.S.-born participants from a different series of sessions of an executive-education program at Harvard participated as part of a larger study at the HDSL. Recruitment occurred under the same condition as before (i.e., in Study 2). The sample consisted of 449 participants $(68 \%$ male; Mage $=47.01$, SDage $=8.67)$ from EuropeanAmerican cultural backgrounds (74\%) and from numerous other cultures (9\% African or African-American, 5\% Latin-American, 5\% Asian, and 7\% other). Sample size was determined based on enrollment in Harvard's Executive Education program. Once more, this sample of professionals and managers represented a highly ecologically valid sample. ${ }^{6}$

\section{Method}

As a measure of empathic accuracy, we presented participants with the "Reading the Mind in the Eyes Test" (RMET; Baron-Cohen et al., 2001), which assesses the ability to recognize complex mental states from limited facial cues. In each of 36 trials, participants viewed a photograph of an individual's eye region and were asked which of four words (e.g., terrified, upset, arrogant, or annoyed) best described the target's current emotional state. Although the "Reading the Mind in the Eyes" test stands as a measure of consensus—namely, the correct answers reflect what a group of observers agreed the people in the images were feeling, rather than the targets' self-assessments (Baron-Cohen et al., 2001), it has been widely used to measure empathic accuracy (e.g., see Mascaro, Rilling, Negi \& Raison, 2012; Ronay \& Carney, 2013; Sherman, Lerner, Renshon, Ma-Kellams \& Joel, 2015).

In addition, participants completed the same CRT measure used in the previous study, demographic questions (e.g., age, gender, educational attainment, English fluency—i.e., whether 
they are a U.S. native), and a subset $(\mathrm{n}=411)$ completed the Wechsler Adult Intelligence Scale, Third Edition (WAIS-III; Wechsler, 1997). Due to omitted responses and the fact that not all questions (i.e., the WAIS-III) were included in every version of the survey, the numbers of responses vary by item.

\section{Results and Discussion}

Correct responses across the 36 trials in the empathic accuracy task were summed to yield an overall measure of empathic accuracy; higher scores reflect greater accuracy. Likewise, responses on the CRT were scored and summed, with higher scores reflecting more correct answers, or higher levels of systematic thinking. Gender was coded dichotomously (women $=1$ and men $=0$ ).

As predicted, CRT performance predicted empathic accuracy on the RMET, $\beta=.12$, $t(447)=2.49, p=.013$. As Figure 2 shows, systematic thinking is positively correlated with empathic accuracy; gains on CRT performance were accompanied by gains on RMET accuracy. An ANOVA comparing empathic accuracy among the four performance categories on the CRT (i.e., those who scored $0,1,2$, or 3 correct) revealed a significant effect on CRT performance, $F(3,445)=2.77, p=.041$. Subsequent Dunnett post-hoc tests corrected for multiple comparisons revealed that those who engaged in the most systematic thinking (i.e., those who scored all three of the CRT items correctly, $n=45)$ were more empathically accurate $(M=26.40, S D=3.88)$ than those who exhibited no systematic thinking (i.e., those who answered no CRT items correctly, $n$ $=208 ; M=24.91, S D=3.74): M$ diff $=-1.49(S E=0.62)$, lower $95 \% \mathrm{CI}=-2.92$, upper $95 \% \mathrm{CI}=$ $-0.056, p=.026, d=.39$. A comparison between those who answered all three CRT items correctly with those who answered one $(n=121, M=25.84, S D=3.68)$ or two items correctly $(n$ 
$=75, M=25.53, S D=4.11$ ) did not reveal a significant difference (both $p$ 's $>.41 ; d$ 's <.22), although the differences between the means were in the same direction; see Figure 2.

The relationship between CRT responses and empathic accuracy remained after controlling for gender, $\beta=.13, t(445)=2.82, p=.005$, despite the previously observed strong relationship between gender and the CRT (Frederick, 2005), which also emerged here ( $\beta=.13$, $t(445)=2.69, p=.007)$; see Table 4 . The effect also remained when other demographic controls were added instead of gender, $\beta=.10, t(434)=2.11, p=.036$ (i.e., age- $\beta=-.05, t(434)=1.05$, $p=.29$, and education $-\beta=.08, t(434)=1.62, p=.10)$. In addition, we tested whether these effects held even when controlling for intelligence. Past studies have shown that intelligence predicts performance on the ability to read emotions from facial expressions and vocal tone (Realo et al., 2003); related studies have shown similar effects of GPA (Ickes et al., 1990) and education (Thomas et al., 1997). Furthermore, intelligence is also associated with CRT performance, although the two are conceptually distinct constructs that are moderately correlated (Frederick, 2005; Obrecht, Chapman \& Gelman, 2009). Given these relationships, we re-ran the regression analyses with performance on the Weschler Adult Intelligence Scale (WAIS-III, 1997) as an additional control. When WAIS scores and fluency are included along with the other significant aforementioned covariate (gender), CRT scores continues to significantly predict empathic accuracy, $\beta=.12, t(297)=2.03, p=.043$, as does WAIS $(\beta=.16, t(297)=2.68, p=$ $.008)$, and gender $(\beta=.16, t(297)=2.73, p=.007)$; see Table 4 .

The findings from Study 3 replicated those from Study 2. Together, the findings from Studies 2 and 3 offer convergent evidence for a robust relationship between systematic thinking and empathic accuracy. However, both studies were correlational in nature. Furthermore, it 
remains unclear what underlying mechanism can account for the effects of systematic thinking on improving empathic accuracy. To address these questions, we conducted Study 4.

\section{Study 4}

Study 4 tests the causal relationship between systematic thinking and empathic accuracy. Here, we experimentally induced a mindset that either favored systematic or intuitive thinking, and subsequently tested its impact on empathic accuracy. We predicted that consistent with the previous individual difference findings, those who engage in systematic thinking will be more accurate at inferring emotions than those who engage in intuitive thinking.

\section{Participants}

A new group of international and U.S.-born participants from a different session of the executive-education program at Harvard University participated as part of a larger study at the HDSL. Recruitment and participation occurred under the same conditions as before (i.e., in Studies 2 and 3) and once more reflected an ecologically valid sample. Those who did not pass comprehension checks (i.e., six who failed to follow the directions) were excluded to maximize the validity and generalizability of our findings, leaving a final sample of 74 participants $(54=$ male; Mage $=48.69$, SDage $=7.28 ; 70 \%$ European-American, $13 \%$ Asian, $12 \%$ African or African-American, 4\% Latin-American, $1 \%$ other). As before, sample size was determined based on enrollment in Harvard's Executive Education program.

\section{Methods}

Upon arrival at the lab, participants were randomly assigned to one of the two experimental conditions, following the procedures outlined by Shenhav et al. (2011). In the intuitive-thinking condition, participants were asked to write about a situation in which following their intuitions or first instincts led them in the right direction and resulted in a positive outcome. 
In the systematic-thinking condition, they were asked to write about a situation in which carefully reasoning through a situation led them in the right direction and resulted in a positive outcome. In both conditions, participants were asked to write approximately 8-10 sentences and given three minutes to complete the task. Participants then completed the same mock interview exercise used in the previous study, followed by a demographics questionnaire. We predicted that the systematic-thinking induction would lead to greater empathic accuracy on the mock interview.

\section{Results and Discussion}

As a manipulation check, integrative complexity of the responses were computed to confirm that those in the systematic thinking actually engaged in more critical and careful reasoning compared to those in the intuitive condition. We chose this manipulation check because it allowed us to test the effectiveness of the experimental induction with a measure that was not prone to demand characteristics. As a dimension of information processing, integrative complexity stands as a measure of the willingness and ability to account for and integrate multiple competing perspectives on the same issue (Suedfeld, Tetlock, \& Streufert, 1992). Two independent coders rated participants' reflections for integrative complexity using a 1 (little or no integration) to 7 (high integration) scale, following the guidelines outlined by Baker-Brown, Ballard, Bluck, De Vries, Suedfeld, \& Tetlock (1992). Scores of 1 reflect information that is presented uni-dimensionally, in an evaluatively consistent and value-laden way-i.e., little or no differentiation or integration, whereas scores of 7 reflect systematic analyses of different principles in a contextual and interactive manner; scores of 3 reflect moderate to high differentiation but no integration, and scores of 5 reflect both differentiation and moderate integration (Baker-Brown et al., 1992). Intercoder reliability was high (alpha $=.88)$, and an 
independent samples t-test revealed no differences in integrative complexity between interviewers and interviewees $(p>.20)$. As expected, those in the systematic-thought condition exhibited greater integrative complexity $(M=3.42, S D=1.46)$ than those in the intuitive-thought condition $(M=2.43, S D=1.21), t(68)=2.48, p=.003, d=.73 .^{7}$

For the main analyses, empathic accuracy scores on the mock interview were computed using the same procedure as before. Running the analyses using intra-class correlation and difference scores yielded the same pattern of results (i.e., condition predicted empathic accuracy, with higher accuracy in the systematic thinking condition: $\beta=.23, t(73)=2.02, p=.048$ for intraclass correlations and $\beta=-.25, t(73)=2.19, p=.032$ for difference scores). Those in the systematic thinking condition exhibited higher correlations $(M=.76, S D=.11)$ and lower difference scores $(M=1.41, S D=0.28)$ than those in the intuitive thinking condition $(M=.66$, $S D=.24$ and $M=1.59, S D=0.40$ for correlations and difference scores, respectively).

\section{General Discussion}

Four studies examined the relationship between intuition and individuals' abilities to empathically infer others' experiences. The first study demonstrated that individuals hold a lay theory that the best way to accurately infer another person's thoughts and feelings is intuitive rather than systematic. Three subsequent studies_-including mid-career executive-level professionals, old and young individuals, U.S. citizens and international visitors-converged on the conclusion that, contrary to this lay belief, systematic thinking, as opposed to intuitive thinking, predicts empathic accuracy. Study 2 showed that those who exhibit more systematic and less intuitive modes of thought are more likely to succeed at a naturalistic and dynamic measure of empathic accuracy: the ability to detect a live partner's emotions during a mock interview. Study 3 replicated these findings using a different measure of empathic accuracy- 
namely, the ability to infer emotions and affect from limited facial cues. Across both studies, these results remained robust even when holding other predictors of intuitive versus systematic thinking and empathic accuracy (e.g., gender, education, power, etc.) constant, suggesting that such mode of thought itself drives the result. Finally, Study 4 demonstrated a causal relationship between induced intuitive versus systematic thinking and empathic accuracy: those experimentally manipulated to be in a mindset favoring systematic thought exhibited better empathic accuracy relative to those induced to be in an intuitive mindset.

Importantly, three out of the four studies presented here relied on actual professionals and managers. In doing so, we demonstrated these effects in an externally valid way. This sample represented a highly relevant group for which to test empathic accuracy given the importance of empathic accuracy for a host of workplace outcomes, including negotiations (Elfenbein et al., 2007; Galinsky et al., 2008; Neale \& Bazerman, 1983), worker satisfaction (Byron, 2007), and workplace performance (Elfenbein \& Ambady, 2002; Rosenthal et al., 1979),

These findings offer important implications for practice. Given the breadth of interpersonal processes that empathic accuracy implicates, it is notable that lay assumptions about what makes a good emotional mind-reader diverge from the empirical evidence. The present findings show that across very different contexts, including mock interviews as well as controlled environments where only limited facial cues are available, an effortful mode of thought is associated with empathic accuracy. Thus, the many settings in which the value of intuition is extolled (e.g., job interviews) may now take a more nuanced view, recognizing that intuition has limited value in some aspects of social interaction. On a larger scale, the aforementioned U.S. federal programs designed to demonstrate the value of intuition in national security settings may need to take a moderated approach, informed by these findings. 
The findings also hold implications and raise questions for theory. The observed relationship between systematic thinking and empathic accuracy may appear puzzling from an evolutionary perspective. Should not these processes be automatic for survival needs? The puzzle can be reconciled by recognizing that empathic accuracy involves both automatic and contextual processes (Zaki, 2014) and that — in modern society - the process of truly and accurately understanding another person's feelings typically entails more elaborate and detailed efforts. Spontaneous mental representations and attention to emotional cues are only the first step in a complex inferential process that includes attending to online external cues, perspectivetaking, and emotion regulation (see Decety \& Jackson, 2004, for review), none of which occur reflexively or automatically but rather require substantive effort and attention.

These arguments notwithstanding, the present findings likely have boundary conditions. For example, there may be instances where stereotypes about the target person's role or group membership accurately reflect a genuine group characteristic; in such instances, systematic thinking may not aid in empathic accuracy. Existing research on "stereotype accuracy" has suggested that a heuristic-style reliance on such pre-existing mental representations may facilitate accuracy in situations where the target behaves in a stereotype-consistent manner (e.g., when inferring the experiences of clinical patients, Gesn \& Ickes, 1999; of spouses, Kilpatrick et al., 2002; and of new mothers, Lewis, Hodges, Laurent, Srivastava, \& Biancarosa, 2012). The same benefits of intuitive thought may hold when inferring feelings of friends - as opposed to strangers (Stinson \& Ickes, 1992). Thus, in cases where: 1) there is a clear, valid, and relevant stereotype that can be applied, and 2) the target acts in accordance with the stereotype, heuristically relying on stereotypes, rather than engaging in systematic thought, may promote increased levels of empathic accuracy. 
In the present study, by contrast, emotional mind-reading occurred in a relatively novel context with an unfamiliar target; perceivers were assigned to read the emotions of strangers based on either severely limited cues (i.e., photographed eyes in Study 3) or in a non-typical laboratory setting (i.e., Studies $2 \& 4$ ). Thus, we acknowledge that the present pattern of results may be applicable primarily to settings where vast and valid preexisting information about targets is not readily available.

The question of why individuals intuitively believe that empathic accuracy benefits from intuition remains. One possibility is that in much of everyday life, people make inferences about targets for which a broad array of preexisting information exists and that, in such situations, opting for the intuitive and stereotypical default may prove to be a useful strategy. At the same time, deficits in empathic accuracy occur when individuals do not sufficiently and systematically adjust from these intuition-based automatic responses when facing a novel situation or target. The myriad examples of interpersonal misunderstanding may reflect such processes.

Limitations. One limitation is that the present studies focused exclusively on empathic accuracy in inferring the emotions of others and did not focus on inferring thoughts of others. To our knowledge, no studies to date have suggested that the process of inferring another person's emotions is distinct from the process of inferring another person's thoughts. Nevertheless, the question of whether our findings would extend to situations where thoughts and not feelings are the primary unit of analysis remains an empirical question to be tested.

Another limitation is that one of the measures of empathic accuracy used in this paper is more accurately described as a measure of perceptual consensus (i.e., the RMET) rather than a measure of the degree to which a perceiver perceives the same emotions as the target. Future 
studies can aim to test other measures of empathic accuracy and emotion recognition to establish the robustness of these effects across different measures of accuracy.

These limitations notwithstanding, it is important to note that our findings contribute to, and are consistent with, a larger body of work on the limitations of individuals' understanding of their own psychological processes. This notable feature of the human psyche has been demonstrated in a number of phenomena, including the introspection illusion (see Pronin, 2009 for review), affective forecasting (see Wilson \& Gilbert, 2005 for review), and lay intuitions about happiness (e.g., see Killingsworth \& Gilbert, 2010).

We contend, however, that the fact that previous studies have found instances where lay intuitions are inaccurate does not negate the need for subsequent studies on the topic of empathic accuracy. After all, many lay theories abound, and a number of them are correct and supported by empirical research (e.g., Fletcher \& Fitness, 1996; Furnham, 1988; Varnum, 2013). The fact that individuals hold an inaccurate lay theory about a process as fundamental and mundane as everyday mind-reading helps to unpack how and why human beings can fail to accurately understand one another.

In sum, the present studies offer convergent evidence for the relationship between empathic accuracy and mode of thought. Across multiple studies - both correlational and experimental — we consistently observed that engaging in systematic, as opposed to intuitive, thinking is associated with increased accuracy when reading the feelings of others. Taken together, these studies contribute to the literature on "everyday mind reading" (Ickes, 2001) by elucidating a crucial cognitive mechanism that goes against lay intuition. 
Footnotes

${ }^{1}$ The term "empathic accuracy" has sometimes been used to describe inferences made about the feelings and thoughts of others (Ickes et al., 1990). In the present paper, we use the term to mean only inferences about the feelings of others.

${ }^{2}$ Following convention in the literature (Chaiken \& Trope, 1999) on dual process theories in social psychology, intuitive processes encompass cognitions that are heuristic, associative, holistic, or experience-based, whereas reflective processes encompass cognitions that are systematic, controlled, analytic, or rule-based.

${ }^{3}$ For more discussion about the potential pitfalls of effortful thought, see Tetlock, Lerner, \& Boettger, 1996; Lerner \& Tetlock, 1999. These findings are consistent with an adjacent body of literature demonstrating that accurate social-judgment processes can in fact rely on automatic processes (for a review, see Bodenhausen \& Todd, 2010). For example, the "thin slices" literature has demonstrated that individuals can make highly accurate, instantaneous evaluations of others' professional competence based on limited cues (for a review, see Ambady \& Skowronski, 2008), including facial cues (Oosterhof \& Todorov, 2008, van'T Wout \& Sanfey, 2008, Zebrowitz \& McDonald, 1991).

${ }^{4}$ The RMET task is best understood as a test of one's ability to infer consensual labels for expressed emotions rather than as a test of ability to infer emotions per se because the correct responses are determined based on modal responses of perceivers rather than on anatomical features of the face displayed.

${ }^{5}$ We also re-ran the logistic regression with gender as an additional factor predicting individuals' lay theories about empathic accuracy; no gender differences emerged.

${ }^{6}$ In order to make maximal use of having a hard-to-access, international population of executivelevel professionals within the controlled environment of a laboratory, multiple researchers inserted self-report measures into the study protocol. These additional measures (inserted by multiple investigators to the master participant protocol from which Study 3 data were drawn, inculudes: Positive and Negative Affect Survey (PANAS; MacKinnon et al., 1999); Emotion Regulation Questionnaire (ERQ; Gross \& John, 2003); Emotion Regulation Self-Efficacy (ERQ-SE; Philippe, et al., 2012); Dispositional Anger Measure (Lerner \& Keltner, 1999);Speilberger Trait Anxiety (STAI; Spielberger, 1983); Wais III Verbal/IQ (Wechsler, 1997); Cognitive Reflection Test (Frederick, 2005); Numeracy (Peters et al., 2006); Status ladder (Adler, Epel, Castellazzo, \& Ickovics, 2000); Dispositional Power (Anderson, 2012).

${ }^{7}$ The analysis for integrative complexity has fewer degrees of freedom because the responses of four participants were un-codeable/left blank.

References 
Agor, W. (1989). The logic of intuition: How top executives make important decisions. In W. Agor (Ed.), Intuition in organizations: Leading and managing productively (pp. 141153). London: Sage

Ambady, N. E., \& Skowronski, J. J. (2008). First impressions. New York, NY: Guilford Publications.

Ames, D. R. (2004a). Inside the mind reader's toolkit: Projection and stereotyping in mental state inference. Journal of Personality and Social Psychology, 87, 340-353.

Anderson, C., Kelter, D., \& John, O. (2003). Emotional convergence over time. Journal of Personality and Social Psychology, 84, 1054-1068.

Avenanti, A., Sirigu, A., \& Aglioti, S. M. (2010). Racial bias reduces empathic sensorimotor resonance with other-race pain. Current Biology, 20, 1018-1022.

Baker-Brown, G., Ballard, E. J., Bluck, S., de Vries, B., Suedfeld, P., \& Tetlock, P. E. (1990). Coding manual for conceptual/integrative complexity. University of British Columbia and University of California, Berkeley.

Baron-Cohen, S., Wheelwright, S., Hill, J., Raste, Y., \& Plumb, I. (2001). The "Reading the mind in the eyes" test revised version: A study with normal adults, and adults with asperger syndrome or high- functioning autism. Journal of Child Psychology and Psychiatry, 42, 241-251.

Bartz, J., Zaki, J., Bolger, N., Hollander, E., Ludwig, N., Kolevzon, A. \& Ochsner, K. (2010). Oxytocin selectively improves empathic accuracy in less socially proficient individuals. Psychological Science, 21, 1426-1428. 
Bombari, D., Schmid Mast, M., Brosch, T. \& Sander, D. (2013). How interpersonal power affects empathic accuracy: differential roles of mentalizing $v s$. mirroring? Frontiers in Human Neuroscience, 7, 375.

Bowers, K. S., Regehr, G., Balthazard, C., \& Parker, K. (1990). Intuition in the context of discovery. Cognitive psychology, 22(1), 72-110.

Burhmester, M.D., Kwang, T., \& Gosling, S.D. (2011). Amazon's Mechanical Turk: A new source of inexpensive, yet high-quality data? Perspectives on Psychological Science, 6, 3-5.

Byron, K. (2007). Male and female managers' ability to read emotions: Relationships with supervisor's performance ratings and subordinates' satisfaction ratings. Journal of Occupational and Organizational Psychology, 80, 713-733.

Cacioppo, J. T., \& Petty, R. E. (1982). The need for cognition. Journal of Personality and Social Psychology, 42(1), 116.

Channing, J. (2012). U.S. Navy Program to Study How Troops Use Intuition. New York Times, March 27, 2012. Retrieved from http://atwar.blogs.nytimes.com/2012/03/27/navyprogram-to-study-how-troops-use-intuition/?_r=1.

Cheng, Y., Lin, C. P., Liu, H. L., Hsu, Y. Y., Lim, K. E., Hung, D., \&Cheng, Y., Lin, C. P., Liu, H. L., Hsu, Y. Y., Lim, K. E., Hung, D., \& Decety, J. (2007). Expertise modulates the perception of pain in others. Current Biology, 17, 1708-1713.

Cikara, M., \& Van Bavel, J. J. (2014). The neuroscience of intergroup relations: An integrative review. Perspectives on Psychological Science, 9, 245-274. 
Côté, S., Kraus, M. W., Cheng, B. H., Oveis, C., van der L.we, I., Lian, H., \& Keltner, D. (2011). Social power facilitates the effect of prosocial orientation on empathic accuracy. Journal of Personality and Social Psychology, 101, 217-232.

Davis, M. H., Conklin, L., Smith, A., \& Luce, C. (1996). The effect of perspective taking on the cognitive representation of persons: A merging of self and other. Journal of Personality and Social Psychology, 70, 713-726.

Dawes, R.M. (1988). Rational choice in an uncertain world. San Diego: Harcourt Brace Jovanovich.

Dawes, R. M., \& Mulford, M. (1996). The false consensus effect and overconfidence: Flaws in judgment, or flaws in how we study judgment? Organizational Behavior and Human Decision Processes, 65, 201-211.

Decety, J., \& Chaminade, T. (2003). When the self represents the other: A new cognitive neuroscience view on psychological identification. Consciousness and cognition, 12(4), 577-596.

Decety, J. \& Jackson, Ph.L (2004). The functional architecture of human empathy. Behavioral Cognitive Neuroscience Review, 3(2), 71-100.

Decety, J., Yang, C. Y., \& Cheng, Y. (2010). Physicians down-regulate their pain empathy response: An event-related brain potential study. NeuroImage, 50, 1676-1682.

Dijksterhuis, A., Bos, M. W., Nordgren, L. F., \& Van Baaren, R. B. (2006). On making the right choice: The deliberation-without-attention effect. Science, 311(5763), 1005-1007.

Einhorn, H.J \& Hogarth, R.M. (1981). Behavioral decision theory: Processes of judgment and choice. Annual Review of Psychology, 32, 53-88. 
Elfenbein, H. A., \& Ambady, N. (2002). Predicting workplace outcomes from the ability to eavesdrop on feelings. Journal of Applied Psychology, 87, 963-971.

Elfenbein, H. A., Foo, M. D., White, J., Tan, H. H., \& Aik, V. C. (2007). Reading your counterpart: The benefit of emotion recognition accuracy for effectiveness in negotiation. Journal of Nonverbal Behavior, 31, 205-223.

Epley, N., Keysar, B., Van Boven, L., \& Gilovich, T. (2004). Perspective taking as egocentric anchoring and adjustment. Journal of Personality and Social Psychology, 87, 327-339.

Epley, N. \& Waytz, A. (2010). Mind perception. In S. T. Fiske, D. T. Gilbert and G. Lindzey: Handbook of Social Psychology, Fifth Edition. Hoboken, NJ: John Wiley \& Sons, pp. 498-541.

Epstein, S., Pacini, R., Denes-Raj, V., \& Heier, H. (1996). Individual difference in intuitiveexperiential and analytical-rational thinking styles. Journal of Personality and Social Psychology 71(2), 390-405.

Evans, J. S. B. (2009). How many dual-process theories do we need? One, two, or many? In J. Evans and K. Frankish (Eds.): In two minds: Dual processes and beyond. New York, NY: Oxford University Press, pp. 33-54.

Fallshore, M., \& Schooler, J. W. (1995). Verbal vulnerability of perceptual expertise. Journal of Experimental Psychology: Learning, Memory, and Cognition, 21, 1608-1608.

Fisher, R., \& Shapiro, D. (2005). Beyond reason: Using emotions as you negotiate. New York, NY, US: Penguin.

Fletcher, G. J., \& Fitness, J. (Eds.). (1996). Knowledge structures in close relationships: A social psychological approach. Mahwah, N.J: L. Erlbaum Associates. 
Frederick, S. (2005). Cognitive reflection and decision making. Journal of Economic Perspectives, 25-42.

Furnham, A. (1988). Lay theories: Everyday understanding of problems in the social sciences. Oxford, England: Pergamon Press.

Galinsky, A. D., Maddux, W. W., Gilin, D., \& White, J. B. (2008). Why it pays to get inside the head of your opponent: The differential effects of perspective taking and empathy in negotiations. Psychological Science, 19, 378-338.

Gazzola, V., Rizzolatti, G., Wicker, B., \& Keysers, C. (2007). The anthropomorphic brain: the mirror neuron system responds to human and robotic actions. NeuroImage, 35(4) 1674-1684.

Gesn, P. \& Ickes, W. (1999). The development of meaning contexts for empathic accuracy: Channel and sequence effects. Journal of Personality and Social Psychology, 77(4), 746761.

Gigerenzer, G. (2007). Gut feelings: The intelligence of the unconscious. New York, NY: Penguin.

Gilbert, D. T., Pelham, B. W., \& Krull, D. S. (1988). On cognitive busy-ness: When person perceivers meet persons perceived. Journal of Personality and Social Psychology, 54, $733-740$.

Gleason, K. A., Jensen-Campbell, L. A., \& Ickes, W. (2009). The role of empathic accuracy in adolescents' peer relations and adjustment. Personality and Social Psychology Bulletin, 35(8), 997-1011. 
Gonzalez, R. \& Griffin, D. (1997). On the statistics of interdependence: Treating dyadic data with respect. In S. Duck (Ed.), Handbook of personal relationships (pp. 271-302). New York, NY: Wiley.

Greene, J.D. (2009) Dual-process morality and the personal/impersonal distinction: A reply to McGuire, Langdon, Coltheart, and Mackenzie. Journal of Experimental Social Psychology, 45, 581-584.

Gutsell, J., \& Inzlicht, M. (2010). Empathy constrained: Prejudice predicts reduced mental simulation of actions during observation of outgroups. Journal of Experimental Social Psychology, 46, 841-845.

Hall, J. A., Blanch, D. C., Horgan, T. G., Murphy, N. A., Rosip, J. C., \& Mast, M. S. (2009). Motivation and interpersonal sensitivity: Does it matter how hard you try? Motivation and Emotion, 33(3), 291-302.

Harris, L. T., \& Fiske, S. T. (2006). Dehumanizing the lowest of the low: Neuroimaging responses to extreme out-groups. Psychological Science, 17, 847-853.

Haugen, P. T., Welsh, D. P., \& McNulty, J. K. (2008). Empathic accuracy and adolescent romantic relationships. Journal of adolescence, 31(6), 709-727.

Haviland, J. M., \& Lelwica, M. (1987). The induced affect response: 10-week-old infants' responses to three emotion expressions. Developmental Psychology, 23, 97-104.

Hein, G., Silani, G., Preuschoff, K., Batson, C. D., \& Singer, T. (2010). Neural responses to ingroup and outgroup members' suffering predict individual differences in costly helping. Neuron, 68, 149-160. 
Hess, U., \& Blairy, S. (2001). Facial mimicry and emotional contagion to dynamic emotional facial expressions and their influence on decoding accuracy. International Journal of Psychophysiology, 40, 129-141.

Hodges, S.D., Lewis, K.L., \& Ickes, W. (2015). The matter of other minds: Empathic accuracy and the factors that influence it. In M. Mikulincer, M.R. Shaver, J.A. Simpson, \& J.F. Dovidio, (Eds.), APA handbook of personality and social psychology, Volume 3: Interpersonal relations (pp. 319-348). Washington, DC: American Psychological Association.

Hogarth, R.M. (1987). Judgment and choice: The psychology of decisions (2nd ed). Chichester, England: Wiley.

Horton, J.J., Rand, D.G. \& Zechauser, R.J. (2011). The online laboratory: Conducting experiments in a real labor market. Experimental Economics, 14, 399-425.

Ickes, W. (Ed.). (1997). Empathic accuracy. New York, NY: Guilford.

Ickes, W. (2001). Measuring empathic accuracy. In J. A. Hall \& F. J. Bernieri (Eds.), Interpersonal sensitivity: Theory and measurement (pp. 219-241). Mahwah, NJ: Lawrence Erlbaum.

Ickes, W., Stinson, L., Bissonnette, V., \& Garcia, S. (1990). Naturalistic social cognition: Empathic accuracy in mixed-sex dyads. Journal of Personality and Social Psychology, $59,730-742$.

Kahneman, D. Slovic, P. \& Tversky, A. (Eds). (1982). Judgment under uncertainty: Heuristics and biases. Cambridge: Cambridge University Press.

Kahneman, D. \& Tversky, A (1979). Intuitive prediction: Biases and corrective procedures. TIMS Studies in Management Science, 12, 313-327. 
Kahneman, D. (2003). A perspective on judgment and choice: mapping bounded rationality. American psychologist, 58(9), 697.

Killingsworth, M. A., \& Gilbert, D. T. (2010). A wandering mind is an unhappy mind. Science, 330(6006), 932-932.

Kilpatrick, S. D., Bissonnette, V. L., \& Rusbult, C. E. (2002). Empathic accuracy and accommodative behavior among newly married couples. Personal Relationships, 9, 369393.

Klein, G. (1998). Sources of power. Cambridge, MA: MIT Press.

Klein, G. (2003). Intuition at work. New York: Bantem Dell.

Klein, K., \& Hodges, S. (2001). Gender differences, motivation, and empathic accuracy: When it pays to understand. Personality and Social Psychology Bulletin, 27, 720-730.

Knoblich, G., Ohlsson, S., \& Raney, G. E. (2001). An eye movement study of insight problem solving. Memory and Cognition, 27, 1000-1009.

Kraus, M. W., Côté , S., \& Keltner, D. (2010). Social class, contextualism, and empathic accuracy. Psychological Science, 21, 1716-1723.

Krueger, J., \& Acevedo, M. (2005). Social projection and the psychology of choice. In M. D. Alicke, D. Dunning, \& J. Krueger (Eds.), The self in social perception (pp. 17-41). New York: Psychology Press.

Lerner, J.S. \& Tetlock, P. E., (1998). Accounting for the effects of accountability. Psychological Bulletin, 125, 255-275.http://dx.doi.org/10.1037/0033-2909.125.2.255

Levenson, R. W., \& Ruef, A. M. (1992). Empathy: A physiological substrate. Journal of Personality and Social Psychology, 63, 234-246. 
Lewis, K. L., Hodges, S. D., Laurent, S., Srivastava, S., \& Biancarosa, G. (2012). Reading between the minds: The use of stereotypes in empathic accuracy. Psychological Science, 23, $1040-1046$.

Leyens, J.-P., Paladino, P. M., Rodriguez-Torres, R., Vaes, J., Demoulin, S., Rodriguez-Perez, A., \& Gaunt, R. (2000). The emotional side of prejudice: The attribution of secondary emotions to ingroups and outgroups. Personality and Social Psychology Review, 4, 186 197.

Lieberman, M.D. (2000). Intuition: A social cognitive neuroscience approach. Psychological Bulletin, 126(1): 109-137.

Lipps, T. (1903). Einfuhlung, innere Nachahmung, und Organempfindungen [Empathy, inner imitation, and physical sensation]. Archiv für Psychologie, 1, 185-204.

Lipps, T. (1907). Das wissen von fremden Ichen [The knowledge of foreign egos]. Psychologische untersuchungen, 1, 694-722.

Lorimer, R., \& Jowett, S. (2009). Empathic accuracy, meta-perspective, and satisfaction in the coach-athlete relationship. Journal of applied sport psychology, 21(2), 201-212.

Lundqvist, L.-O. (1995). Facial EMG reactions to facial expressions: A case of facial emotional contagion? Scandinavian Journal of Psychology, 36, 130-141.

Ma-Kellams, C. \& Blascovich, J. (2012). The ironic effect of financial incentive on empathic accuracy. Journal of Experimental Social Psychology, 49 (1), 65-71.

Ma-Kellams, C., \& Blascovich, J. (2012). Reading the emotions of friends vs. strangers: Culture and self-construal moderate empathic accuracy. Personality and Social Psychology Bulletin, 38(7), 933-945. 
Macrae, C. N., \& Lewis, H. L. (2002). Do I know you? Processing orientation and face recognition. Psychological Science, 13(2), 194-196.

Marquié, L., Raufaste, E., Lauque, D., Mariné, C., Ecoiffier, M., \& Sorum, P. (2003). Pain

rating by patients and physicians: Evidence of systematic pain miscalibration. Pain, 102, 289 296.

Mascaro, J. S., Rilling, J. K., Negi, L. T., \& Raison, C. (2012). Compassion meditation enhances empathic accuracy and related neural activity. Social Cognitive and Affective Neuroscience, nss095.

Mason, W. \& Suri, S. (2012). Conducting behavioral research on Amazon's Mechanical Turk. Behavioral Research Methods, 44, 1-23.

Mayer, R. E. (1996). The search for insight: Grappling with gestalt psychology's unanswered questions. In R. J. Sternberg \& J. E. Davidson (Eds.), The nature of insight (pp. 3-32). Cambridge, MA: The MIT Press.

McDougall, W. (2003). An introduction to social psychology. New York, NY: Dover. (Original work published 1908).

Mehrabian, A., \& Reed, H. (1968). Some determinants of communication accuracy. Psychological Bulletin, 70, 365-384.

Mitchell, J. P. (2009). Inferences about mental states. Philosophical Transactions of the Royal Society of London: Series B. Biological Sciences, 364, 1309-1316.

Monin, M. (2006). Staff sergeant's suspicion of civilian led to evacuation of Iraq Internet cafe before blast. Stars and Stripes, April 22, 2006. Retrieved from http://www.stripes.com/news/staff-sergeant-s-suspicion-of-civilian-led-to-evacuation-ofiraq-internet-cafe-before-blast-1.48006. 
Myers, D. G. (2002). Intuition: Its powers and perils. New Haven and London: Yale University Press. p. 33.

Myers, M. W., \& Hodges, S. D. (2009). Making it up and making do: Simulation, imagination and empathic accuracy. In K. Markman, W. Klein, \& J. Suhr (Eds.), The handbook of imagination and mental simulation (pp. 281-294). New York: Psychology Press.

Neale, M. A., \& Bazerman, M. H. (1983). The role of perspective taking ability in negotiating under different forms of arbitration. Industrial and Labor Relations Review, 36, 378-38.

Niedenthal, P. M., Brauer, M., Halberstadt, J. B. \& Innes-Ker, Å. H. (2001). When did her smile drop? Facial mimicry and the influences of emotional state on the detection of change in emotional expression. Cognition and Emotion, 15, 853-864.

Nisbett, R. E., \& Wilson, T. D. (1977). Telling more than we can know: Verbal reports on mental processes. Psychological Review, 84, 231-259.

Obrecht, N. A., Chapman, G. B., \& Gelman, R. (2009). An encounter frequency account of how experience affects likelihood estimation. Memory \& cognition, 37(5), 632-643.

Papp, L., Kouros, C., \& Cummings, M. (2010). Emotions in marital conflict interactions: Empathic accuracy, assumed similarity, and the moderating context of depressive symptoms. Journal of Social and Personal Relationships, 27, 367-387.

Paolacci, G., Chandler, J. \& Ipeirotis, P.G. (2010). Running experiments on Amazon Mechanical Turk. Judgment and Decision-Making, 5, 411-419.

Pickett, C., Gardner, W., \& Knowles, M. (2004). Getting a cue: The need to belong and enhanced social sensitivity to social cues. Personality and Social Psychology Bulletin, 9, 1095-1107. 
Preston, S. D., \& De Waal, F. (2002). Empathy: Its ultimate and proximate bases. Behavioral and brain sciences, 25, 1-20.

Pronin, E. (2009). The introspection illusion. In M. P. Zanna (Ed.), Advances in Experimental Social Psychology (Vol. 41, pp. 1-67). San Diego, CA: Academic Press.

Rand, D. \& Epstein, Z.G. (2014). Risking your life without a second thought: Intuitive decision making and extreme altruism. PLOS ONE, 9, e109687.

Realo, A., Allik, J., Nõlvak, A., Valk, R., Ruus, T., Schmidt, M., \& Eilola, T. (2003). Mindreading ability: Beliefs and performance. Journal of Research in Personality, 37(5), 420-445.

Ronay, R., \& Carney, D. R. (2013). Testosterone's negative relationship with empathic accuracy and perceived leadership ability. Social Psychological and Personality Science, 4(1), 92-99.

Rosenthal, R., Hall, J. A., DiMatteo, M. R., Rogers, P. L., \& Archer, D. (1979). Sensitivity to nonverbal communication: The PONS test. Baltimore, MD: Johns Hopkins University Press.

Schooler, J. W. (2002). Verbalization produces a transfer inappropriate processing shift. Applied Cognitive Psychology, 16(8), 989-997.

Schooler, J. W., \& Engstler-Schooler, T. Y. (1990). Verbal overshadowing of visual memories: Some things are better left unsaid. Cognitive Psychology, 22, 36-71.

Schooler, J. W., Ohlsson, S., \& Brooks, K. (1993). Thoughts beyond words: When language overshadows insight. Journal of Experimental Psychology: General, 122, 166-183. 
Schooler, J. W., Ryan, R. S., \& Reder, L. (2014). The costs and benefits of verbally rehearsing memory for faces. Basic and Applied Memory Research: Volume 1: Theory in Context; Volume 2: Practical Applications, 51.

Shenhav, A.S., Rand, D.G., Greene, J.D. (2011 ePub, 2012) Divine intuition: Cognitive style influences belief in God. Journal of Experimental Psychology: General, 141(3) 423-8.

Sherman, G. D., Lerner, J. S., Renshon, J., Ma-Kellams, C., \& Joel, S. (2015). Perceiving others' feelings: The importance of personality and social structure. Social Psychological and Personality Science, 6, 559-569.

Simpson, J. A., Kim, J. S., Fillo, J., Ickes, W., Rholes, W. S., Oriña, M. M., \& Winterheld, H. A. (2011). Attachment and the management of empathic accuracy in relationship-threatening situations. Personality and Social Psychology Bulletin, 37(2), 242-254.

Sloman, R., Rosen, G., Rom, M., \& Shir, Y. (2005). Nurses' assessment of pain in surgical patients. Journal of Advanced Nursing, 52, 125-132.

Slovic, P., Fischhoff, B. \& Lichenstein, S. (1977). Behavioral decision making. Review of Psychology, 28, 1-39.

Smith, A. (2002). The theory of moral sentiments. Cambridge, United Kingdom: Cambridge University Press. (Original work published 1790).

Soto, J. A., \& Levenson, R. W. (2009). Emotion recognition across cultures: The influence of ethnicity on empathic accuracy and physiological linkage. Emotion, 9(6), 874.

Stanovich, K. E., \& West, R. F. (1998). Individual differences in rational thought. Journal of experimental psychology: general, 127(2), 161. 
Sternberg, R. J., \& Grigorenko, E. L. (1997). Are cognitive styles still in style? American Psychologist, 52(7), 700-712.

Stinson, L., \& Ickes, W. (1992). Empathic accuracy in the interactions of male friends versus male strangers. Journal of Personality and Social Psychology, 62, 787-797.

Suedfeld, P., Tetlock, P. E., \& Streufert, S. (1992). Conceptual/integrative complexity. In C. P. Smith, J. W. Atkinson, D. C. McClelland, \& J. Veroff (Eds.), Motivation and personality: Handbook of thematic content analysis (pp. 393-400). New York, NY: Cambridge University Press.

Tetlock, P. (1983). Accountability and complexity of thought. Journal of Personality and Social Psychology, 45(1), 74-83.

Tetlock, P. E., Lerner, J. S., \& Boettger, R. (1996) The dilution effect: judgmental bias, conversational convention, or a bit of both? European Journal of Social Psychology, 26, 915-934.

Tadmor, C. T., Galinsky, A. D., \& Maddux, W. W. (2012). Getting the most out of living abroad: Biculturalism and integrative complexity as key drivers of creative and professional success. Journal of Personality and Social Psychology, 103(3), 520.

Thomas, G., Fletcher, G. J., \& Lange, C. (1997). On-line empathic accuracy in marital interaction. Journal of Personality and Social Psychology, 72(4), 839.

Titchener, E. B. (1909). Lectures on the experimental psychology of the thought processes. New York, NY: Macmillan.

Toplak, M. E., West, R. F., \& Stanovich, K. E. (2011). The Cognitive Reflection Test as a predictor of performance on heuristics-and-biases tasks. Memory \& Cognition, 39(7), $1275-1289$. 
Van't Wout M \& Sanfey, A.G. (2008). Friend of Foe: The effect of implicit trustworthiness judgments in social decision-making. Cognition, 108, 796-803

Varnum, M. E. (2013). What are lay theories of social class?. PloS one, 8(7), e70589.

Verhofstadt, L.L., Buysse, A., Ickes, W., Davis, M., \& Devoldre, I. (2008). Support provision in marriage: The role of emotional similarity and empathic accuracy. Emotion, 8, 792-802.

Volz, K. G., \& von Cramon, D. Y. (2006). What neuroscience can tell about intuitive processes in the context of perceptual discovery. Journal of Cognitive Neuroscience, 18(12), 20772087.

Watson, D., Clark, L.A. \& Tellegen, A. (1988). Development and validation of brief measure of positive and negative affect: the PANAS scales. Journal of Personality and Social Psychology, 54, 1063-1070.

Wilson, T. D., \& Gilbert, D. T. (2005). Affective forecasting knowing what to want. Current Directions in Psychological Science, 14(3), 131-134.

Wilson, T. D., \& Schooler, J. W. (1991). Thinking too much: Introspection can reduce the quality of preferences and decisions. Journal of Personality and Social Psychology, 60, $181-192$.

Xu, X., Zuo, X., Wang, X., \& Han, S. (2009). Do you feel my pain? Racial group membership modulates empathic neural responses. Journal of Neuroscience, 29, 8525-8529.

Zaki, J. (2014). Empathy: A motivated account. Psychological Bulletin, 140, 1608-1647.

Zaki, J., Weber, J., Bolger, N., \& Ochsner, K. (2009). The neural bases of empathic accuracy. Proceedings of the National Academy of Sciences,106(27), 11382-11387. 
Figure 1. The frequency of correct responses on the Cognitive Reflection Test was correlated with absolute difference scores on the empathic accuracy measure, the mock interview.

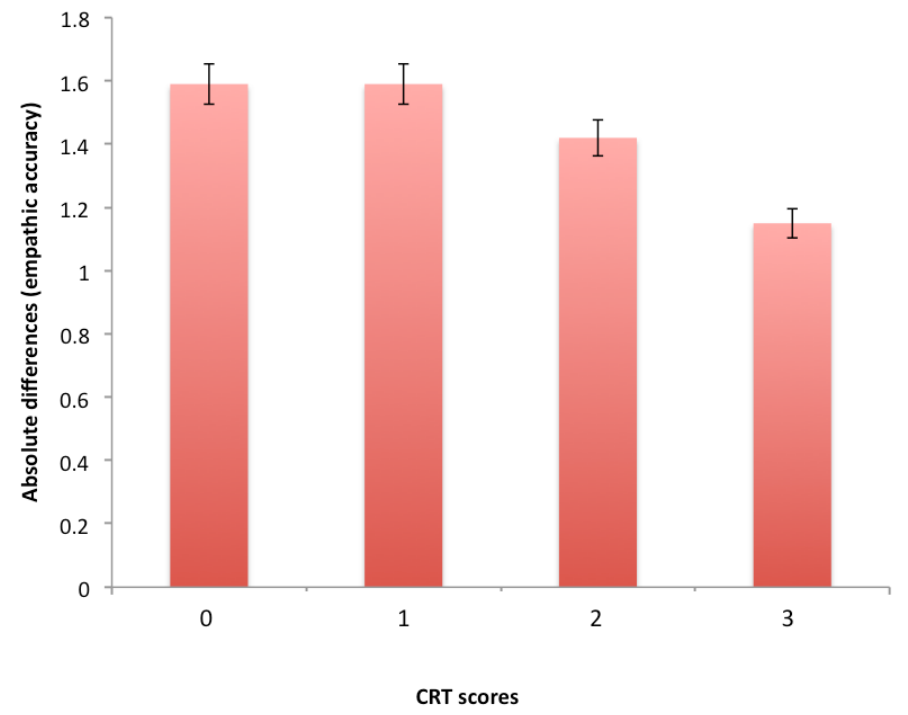


Figure 2

The frequency of correct responses on the Cognitive Reflection Test was positively correlated with performance on the "Reading the Mind in the Eyes" task.

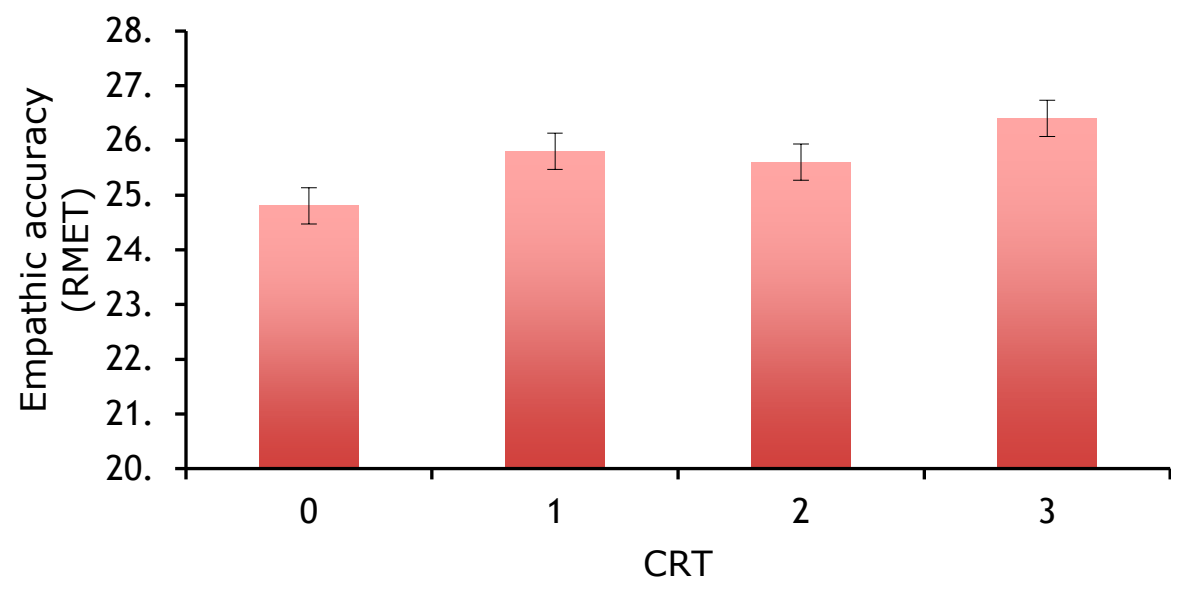


Table 1

Correlations between CRT performance, empathic accuracy (EA) on mock interview (absolute difference scores vs. intraclass correlations), and additional variables (Study 2)

Variable

1. CRT_correct responses

2. EA-Absolute differences

3. EA Intraclass correlations

4. Gender

5. Power (structural)
1

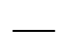

$-.34 * *$

$.24 *$

$-.23 *$

$-.20 \dagger$
2
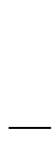

$-.79 * *$

.045

.11
3

4

(1)

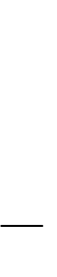

$-10$

$-.10$

Note. CRT = Cognitive Reflection Test (Frederick, 2005). Absolute differences $=$ averaged absolute deviations from partner on the mock interview task. For brevity, we include here only variables that are at least marginally related to either CRT or empathic accuracy. Gender was coded as $1=$ female.

$\dagger \mathrm{p}<.10 * \mathrm{p}<.05 \quad * * \mathrm{p}<.01$ (two-tailed). 
Table 2

Systematic (versus intuitive) thinking, as measured the CRT, predicts intra-class correlations between each participant's inferences about his/her partner's emotions and that partner's actual self-reported emotions (Study 2).

\begin{tabular}{llll}
\hline Predictor & B & t-value & p-value \\
\hline CRT & .24 & 2.07 & .042 \\
CRT+age & .26 & 2.18 & .033 \\
CRT+gender & .23 & 1.92 & .059 \\
CRT+gender, age & .25 & 2.04 & .045 \\
CRT+age, education & .24 & 2.04 & .046 \\
CRT+age, education, gender & .23 & 1.87 & .066 \\
& & & \\
CRT + structural power & .24 & 2.04 & .045 \\
CRT + situational power & .23 & 1.98 & .052 \\
\end{tabular}

$\underline{\text { Table } 3}$

Systematic (versus intuitive) thinking, as measured the CRT, predicts absolute differences between each participant's inferences about his/her partner's emotions and that partner's actual self-reported emotions (Study 2).

\begin{tabular}{llll}
\hline Predictor & B & t-value & p-value \\
\hline CRT & -.33 & 2.96 & .004 \\
CRT+age & -.34 & 2.95 & .004 \\
CRT+gender & -.34 & 2.92 & .005 \\
CRT+gender, age & -.34 & 2.93 & .005 \\
CRT+age, education & -.32 & 2.79 & .007 \\
CRT+age, education, gender & -.33 & 2.74 & .008 \\
& & & \\
CRT + structural power & -.32 & 2.78 & .007 \\
CRT + situational power & -.34 & 2.95 & .004 \\
\hline
\end{tabular}


Note. $C R T=$ Cognitive Reflection Test (higher scores $=$ higher systematicity of thought). Gender is coded as $1=$ female, $0=$ male.

Structural power refers to number of subordinates a person oversees in his/her workplace. Situational power refers to interviewer role $(1=$ interviewer, $0=$ interviewee $)$.

Table 4

Linear regression results reveal that systematic (versus intuitive) thinking, as measured by the CRT, predicts higher scores on the Reading the Mind in the Eyes Test (RMET; Study 3).

\begin{tabular}{llll}
\hline Predictor & $B$ & t-value & p-value \\
\hline CRT & .12 & 2.48 & .013 \\
CRT+age & .11 & 2.38 & .018 \\
CRT+gender & .13 & 2.82 & .005 \\
CRT+ gender, age & .14 & 2.86 & .004 \\
CRT+ gender, intelligence, fluency & .12 & 2.03 & .043 \\
CRT+age, education & .10 & 2.10 & .036 \\
CRT+age, education, gender & .13 & 2.59 & .010
\end{tabular}

Note. $C R T=$ Cognitive Reflection Test (higher scores = higher systematicity of thought).

Gender is coded as $1=$ female, $0=$ male.

Intelligence is measured by the WAIS-III.

Education is measured by level of educational attainment.

Fluency is measured by U.S. native status.

Table 5

Correlations between CRT performance, empathic accuracy on RMET, and demographic variables (Study 3)

Variable

1

2

3

4

1. CRT_correct responses

2. RMET

$.12 *$

3. Gender

$-.11 *$

$.11^{*}$ 
4. Education $\quad .15^{* *} \quad .091^{*} \quad-.008$

Note. CRT = Cognitive Reflection Test (Frederick, 2005). RMET = "Reading the Mind in the Eyes" (Baron-Cohen, 2001). For brevity, we include here only variables that predict empathic accuracy when all other variables are included. $* \mathrm{p}<.05 \quad * * \mathrm{p}<.01$ (two-tailed) 